\title{
RANCANG BANGUN KEANGGOTAAN PERPUSTAKAAN STT TELEMATIKA TELKOM MENGGUNAKAN RFID BERBASIS JAVA 2 STANDARD EDITION DENGAN KONSEP CLIENT SERVER
}

\author{
Yana Yuniarsyah ${ }^{1}$, Elisa Usada ${ }^{2}$, Ahya Amalina ${ }^{3}$ \\ Program Studi Diploma III Teknik Telekomunikasi, Purwokerto \\ ${ }^{1,2,3}$ Sekolah Tinggi Teknologi Telematika TELKOM Purwokerto \\ 1 $\underline{\text { sawahlega@yahoo.com, }}$ elisa@ $\underline{\text { stttelematikatelkom.ac.id, }}, \underline{\text { d } 309005 @ \text { yahoo.com }}$
}

\begin{abstract}
ABSTRAK
Teknologi RFID merupakan teknologi baru yang belum banyak diterapkan. Adanya teknologi ini dapat mengurangi kelemahan dari teknologi barcode. Salah satu penerapan teknologi RFID digunakan untuk kartu anggota perpustakaan. Perpustakaan STT Telematika merupakan perpustakaan yang menggunakan kartu anggota untuk transaksi peminjaman dan pengembalian saja. Adanya teknologi RFID pada kartu anggota dapat menciptakan kartu yang multifungsi, selain digunakan untuk transaksi peminjaman dan pengembalian buku, kartu anggota dapat digunakan untuk absensi pengunjung. Pendistribusian absensi pengunjung dan laporan perpustakaan ini dengan memanfaatkan konsep client-server, sehingga memudahkan pustakawan dalam pengelolaan data. Bahasa pemrograman yang digunakan dalam pembuatan Sistem Informasi Perpustakaan adalah Java 2 Standard Edition (J2SE) dengan menggunakan NetBeans 7.0 sebagai IDE. Penyimpanan database Perpustakaan menggunakan database MySQL. Metode perancangan perangkat lunak untuk pembuatan program dengan menggunakan model waterfall atau linear sequential. Model perancangan untuk pembuatan sistem informasi perpustakaan menggunakan Unified Modelling Language (UML) seperti diagram usecase, diagram activity, dan diagram class. Model perancangan database dengan menggunakan Entity Relationship Diagram (ERD) untuk pengembangan sistem informasi perpustakaan. Pengujian sistem informasi perpustakaan yang digunakan adalah pengujian terhadap user requirement, pengujian terhadap program dengan menggunakan pengujian blacbox, dan pengujian terhadap pengguna. RFID yang digunakan untuk sistem informasi perpustakaan berupa RFID reader yang digunakan untuk membaca informasi yang dibawa oleh RFID tag dan RFID tag yang digunakan untuk untuk memancarkan informasi ke RFID reader. Keberhasilan konsep clientserver berasal dari keberhasilan absensi pengunjung dan menampilkan laporan yang dilakukan dari client, serta keberhasilan server untuk menyimpan data absensi pengunjung yang berasal dari client.
\end{abstract}

Kata Kunci : RFID Perpustakaan, Sistem Informasi Perpustakaan

\begin{abstract}
RFID technology is a new technology that hasn't been widely applied. The existence of this technology can reduce the disadvantages of barcode technology. One application of RFID technology is used for a library card. STT Telematika Library is a library that uses a membership card to borrow and return transactions only. The existence of RFID technology in the card member can create a multifunctional card, in addition to borrow and return books transactions, membership cards can be used for visitor attendance too. Distribution of visitor attendance and report library using client-server concept, thus make it easier for librarians in data management. The programming language used in the design of Library Information System is a Java 2 Standard Edition (J2SE) using NetBeans 7.0 as IDE. Storage Library using the MySQL database. Software design method using waterfall or linear sequential models. Model design to make information sistem using Unified Modeling Language (UML) like usecase diagram, activity diagram, and class diagram. Database design model using Entity Relationship Diagram (ERD) for development information library system. Testing library information system have form with testing user requirements, test the program using blacbox testing, and testing the user. RFID used for library information systems have form such as RFID reader which used to read the information carried by the RFID tag and RFID tag used to transmit information to the RFID reader. The success of the client-server concept comes from the success of visitor attendance and show a report from the client, and the success of server to store visitor attendance data.
\end{abstract}

Keywords : RFID Library, Library Information System 


\section{PENDAhuluaN}

\subsection{Latar Belakang}

Perkembangan teknologi yang semakin canggih memungkinkan banyak akses dalam pencarian informasi dari segala penjuru. Salah satu teknologi yang digunakan untuk pencarian informasi adalah barcode. Beberapa instasi maupun perusahaan banyak menggunakan teknologi barcode sebagai teknologi untuk mempercepat dalam proses transaksi data. Akhir-akhir ini perkembangan barcode mulai ditinggalkan, karena barcode memiliki keterbatasan dalam penyimpanan data dan memerlukan kontak langsung dengan reader, sehingga memerlukan waktu yang agak lama pada transaksi data dalam jumlah yang besar. Kekurangan teknologi ini, memunculkan suatu solusi untuk menciptakan teknologi baru yaitu RFID (Radio Frequency Identification).

RFID merupakan teknologi identifikasi yang menggunakan gelombang radio. Teknologi RFID dapat mengidentifikasi berbagai objek tanpa melakukan kontak secara langsung (contacless). Perkembangan RFID merupakan penggganti atau penerus teknologi barcode. Implementasi RFID ini efektif digunakan untuk instasi maupun perusahaan yang memerlukan akurasi dan kecepatan dalam identifikasi data dalam jumlah yang besar. Sistem RFID memiliki dua bagian yang terpenting yaitu RFID tag dan RFID reader. RFID reader digunakan untuk membaca sinyal berupa data yang berasal dari RFID tag. RFID tag berisi antena yang berfungsi untuk menerima dan merespon terhadap suatu query yang dipancarkan oleh suatu RFID reader. Data yang diterima oleh RFID reader ini kemudian dapat ditampilkan pada komputer untuk mengetahui nomor seri yang tertera pada RFID tag. RFID tag memiliki beberapa jenis diantaranya berbentuk kartu, stiker, gantungan kunci dan lain-lain. Penerapan RFID di Indonesia sudah cukup banyak yaitu terdapat kartu jalan tol, supermarket, perpustakaan dan sebagainya. ${ }^{[24]}$

Implementasi teknologi pada perpustakaan tergolong masih baru. Penerapan teknologi ini dapat menciptakan perpustakaan yang lebih modern. Implementasi RFID pada perpustakaan ini tengah menjadi trend karena memiliki keunggulan dari barcode. RFID yang terdapat perpustakaan salah satunya digunakan untuk nomor pada kartu anggota untuk mengidentifikasi bahwa pengguna merupakan anggota dari perpustakaan tersebut. Kartu anggota tersebut akan mempermudah pengguna dalam proses peminjaman buku.

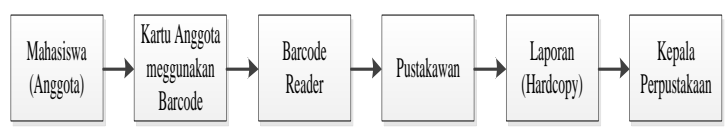

Gambar 1. Sistem Perpustakaan Menggunakan Barcode

Proses peminjaman pada perpustakaan STT TELEMATIKA Purwokerto seperti pada gambar 1 Mahasiswa atau anggota datang dengan mengisi buku daftar pengunjung secara 
manual. Ketika mahasiswa melakukan peminjaman buku menggunakan kartu anggota dalam bentuk barcode, barcode reader membaca kode yang tertera pada kartu anggota melalui sinyal berupa infra merah. Pengarahan barcode reader ini harus tepat pada kode yang tertera pada kartu anggota, sehingga membutuhkan waktu yang agak lama apabila tidak tepat pada sasaran, selain itu kode pada barcode mudah rusak. Data yang terbaca pada barcode reader, maka ditampilkan pada komputer pustakawan untuk melakukan proses data peminjaman. Pustakawan tidak hanya melakukan proses peminjaman, tetapi setiap harinya harus melakukan rekap data untuk dilaporkan tiap bulanan kepada Kepala Perpustakaan. Pelaporan ini masih manual karena harus melakukan rekap data peminjaman setiap harinya, rekap data kunjungan perpustakaan tiap harinya, dan penyampaian laporan bulanan dalam bentuk hardcopy dan softcopy (dalam bentuk Microsoft Excel). Proses ini membutuhkan waktu yang terlalu banyak, sehingga penulis memiliki inisiatif untuk menerapkan teknologi baru yaitu teknologi RFID pada proses peminjaman dan sistem absensi kunjungan perpustakaan. Penggunaan teknologi ini akan lebih efektif dan efisien dalam pelaksanaan proses tersebut.

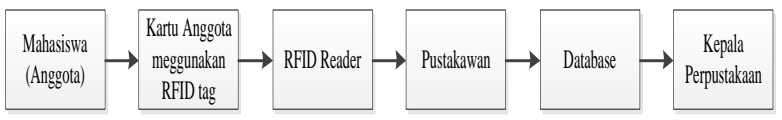

Gambar 2. Sistem Perpustakaan

Menggunakan RFID
Proses peminjaman pada menggunakan RFID seperti gambar 2 adalah mahasiswa atau anggota datang melakukan absensi pengunjung dengan menggunakan kartu anggota berbentuk RFID tag dan diarahkan ke RFID reader. Ketika mahasiswa tersebut akan melakukan proses peminjaman buku menggunakan kartu anggota, maka proses peminjaman dilakukan dengan cepat karena tidak perlu melakukan kontak secara langsung (contacless). RFID reader dapat membaca semua RFID tag yang masih berada dalam jangkauannya. Seperti pada barcode, data yang terbaca oleh RFID reader kemudian ditampilkan pada komputer untuk melakukan proses data peminjaman. Untuk pelaporan data tiap bulannya dilakukan secara otomatis (menggunakan database dari MySQL), karena rekap data didistribusikan melalui protokol TCP/IP (Transmission Control Protocol/Internet Protocol). Komputer pustakawan merupakan komputer server dan komputer kepala perpustakan merupakan komputer client, sehingga kepala perpustakaan dapat memonitor data perpustakaan secara otomatis.

\subsection{Perumusan Masalah}

Permasalahan yang dapat dikaji lebih lanjut dari latar belakang diatas sebagai berikut :

1. Bagaimana merancang dan mengimplementasikan suatu Sistem Informasi Perpustakaan STT 
TELEMATIKA Purwokerto dengan menggunakan RFID.

2. Bagaimana pemanfaatan teknologi RFID untuk dapat diintegrasikan dengan Sistem Informasi Perpustakaan STT TELEMATIKA Purwokerto.

3. Bagaimana penggunaan konsep client server pada pendistribusian data hasil pengolahan aplikasi Sistem Informasi secara terpusat.

\subsection{Maksud dan Tujuan Penulisan}

Adapun maksud dan tujuan dari Tugas Akhir ini adalah pemanfaatan teknologi RFID pada Sistem Informasi Perpustakaan STT Telematika Purwokerto dengan memanfaatkan konsep client server pada pelaporannya.

\subsection{Batasan Masalah}

Batasan masalah yang ada dalam Tugas Akhir ini adalah sebagai berikut :

1. Pembuatan aplikasi Sistem Informasi Perpustakaan STT Telematika mencakup pada absensi kunjungan mahasiswa dan proses peminjaman menggunakan kartu anggota.

2. Pendistribusian laporan perpustakaan dan absensi pengunjung memanfaatkan konsep client server.

3. Database yang digunakan untuk penyimpanan data adalah MySQL.

4. Jenis teknologi RFID yang digunakan untuk mendeteksi keanggotaan perpustakaan STT Telematika adalah RFID reader dengan RFID tag yang berupa kartu.
5. Bahasa pemrograman yang digunakan adalah Java Standard Edition.

6. NetBeans IDE 7.0 sebagai IDE (Integrated Development Environment)

\subsection{Manfaaat Penulisan}

Manfaat yang dapat diambil dari Tugas Akhir ini adalah :

1. Mempermudah pustakawan untuk pengelolaan administrasi di perpustakaan STT Telematika seperti keanggotan dan proses peminjaman.

2. Mempermudah pustakawan untuk mengetahui pengunjung perpustakaan STT Telematika dalam 1 hari.

3. Mempermudah kepala perpustakaan dalam memonitor data perpustakaan dengan menggunakan konsep client server.

\section{DASAR TEORI}

\subsection{Sistem Informasi}

Sistem informasi merupakan suatu sistem dalam suatu organisasi yang mempertemukan kebutuhan pengolahan transaksi harian, dimana transaksi ini mendukung fungsi operasi organisasi yang bersifat manajerial dengan kegiatan strategi dari suatu organisasi untuk dapat menyediakan kepada pihak luar tertentu dengan informasi yang diperlukan untuk keputusan. $^{[22]}$

\subsection{Rekayasa Perangkat Lunak}

Rekayasa Perangkat Lunak adalah pendekatan sistematis dan matematis untuk membangun, memelihara, dan 
mengenyahkan perangkat lunak sehingga menghasilkan perangkat lunak yang bermutu, tepat waktu dengan biaya yang optimal. ${ }^{[7]}$

\subsection{Java}

Java adalah bahasa pemrograman berorientasi objek murni yang dibuat berdasarkan kemampuan-kemampuan terbaik bahasa pemrograman objek sebelumnya seperti $\mathrm{C}++$, Ada, Simula, dan sebagainya. ${ }^{[21]}$

\subsection{Gelombang Radio}

Gelombang radio adalah gelombang yang terdiri dari getaran (osilasi) cepat pada medan elektrik maupun magnetik. ${ }^{[14]}$

\subsection{Radio Frequency Identification (RFID)}

Menurut Bhatt dan Glover (2006) bahwa definisi RFID adalah sistem identifikasi yang berfungsi saat suatu perangkat elektronika didekatkan benda yang ingin diidentifikasi menggunakan frekuensi radio atau variasi medan magnet. $^{[12]}$

\subsection{MySQL}

MySQL merupakan perangkat lunak atau software sistem manajemen basis data SQL (Structured Query Language) atau DBMS (Database Managemen System) yang multithread dan multiuser. ${ }^{[1]}$

\subsection{Client-Server}

Client-Server adalah sebuah arsitektur jaringan yang memisahkan antara client dengan server. ${ }^{[8]}$
2.8. Transmission Control Protocol/Internet Protocol (TCP/IP)

TCP/IP merupakan sekelompok protokol yang memungkinkan kumpulan komputer untuk berkomunikasi dan bertukar data dalam suatu jaringan pada umumnya dan internet pada khususnya. Apabila suatu komputer terhubung dengan internet, maka komputer tersebut dapat berhubungan dengan komputer lain dibelahan dunia manapun. ${ }^{[5]}$

\section{PERANCANGAN SISTEM}

Perancangan perangkat lunak menggunakan model waterfall seperti pada gambar 3. Model waterfall memiliki sifat yang sistematis dan beraturan dalam membangun suatu perangkat lunak. Model ini juga melakukan pengerjaan sistem secara berurutan atau linier. Terdapat 5 tahapan proses yang digunakan oleh model ini, yaitu analisa kebutuhan perangkat lunak, perancangan sistem, pembuatan kode program, pengujian program, dan penerapan program.

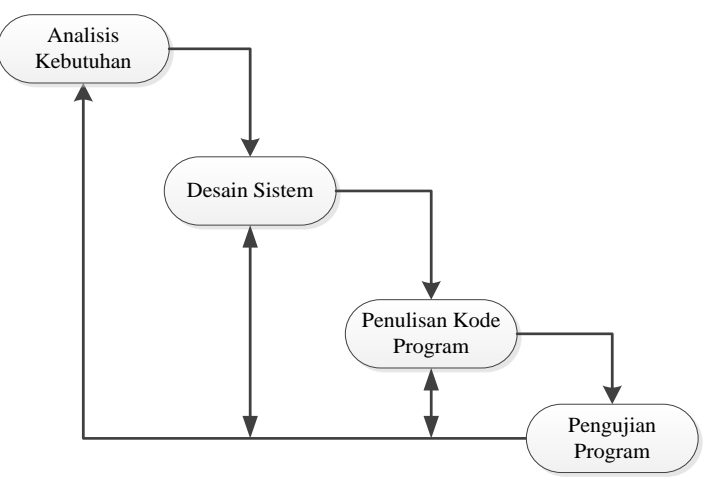

Gambar 3. Alur Sistem Informasi 


\subsection{Analisis Kebutuhan Sistem}

1. Instrument Penelitian

Instrumen penelitian adalah segala peralatan yang digunakan untuk membantu proses pembuatan suatu program atau aplikasi. Instrumen penelitian yang digunakan dalam pembuatan tugas akhir ini adalah :

a. Software

1) Java Development Kit (JDK) 6 update 25.

2) NetBeans IDE 7.0.

3) MySQL server versi 5.5.16.

b. Hardware
1) Laptop
2) RFID

2. Metode Pengumpulan Data

a. Observasi

Observasi yang dilakukan dalam pembuatan tugas akhir ini adalah dengan mengamati proses maupun cara kerja sistem yang terdapat pada Perpustakaan STT Telematika Purwokerto.

b. Wawancara

Wawancara dilakukan kepada anggota, pustakawan dan kepala perpustakaan di Perpustakaan STT Telematika Purwokerto untuk mengetahui proses pendataan pada perpustakaan.

c. Studi Literatur

Studi literatur yang digunakan dalam proses pembuatan tugas akhir yaitu dengan mencari referensi mengenai Sistem Informasi, Konsep
Basis Data (Database),

Pemrograman Java, dan RFID.

d. User Leveling

1) Pustakawan atau admin

Pustakawan diperbolehkan untuk mengelola seluruh data perpustakaan.

2) Anggota

Anggota diperbolehkan untuk melakukan absensi, peminjaman, dan pengembalian buku.

3) Kepala Perpustakaan

Kepala Perpustakaan diperbolehkan untuk menerima laporan.

\subsection{Perancangan Sistem Informasi}

1. Unified Modeling Language (UML)

Unified Modeling Language (UML) merupakan bahasa standart untuk melakukan spesifikasi, visualisasi, konstruksi dan dokumentasi dari komponen-komponen perangkat lunak, dan digunakan untuk pemodelan. [20]

Diagram UML yang digunakan dalam pembuatan aplikasi sistem informasi perpustakaan menggunakan diagram use case, diagram activity, dan diagram class. Penggambaran diagram seperti yang digambarkan dibawah ini : 


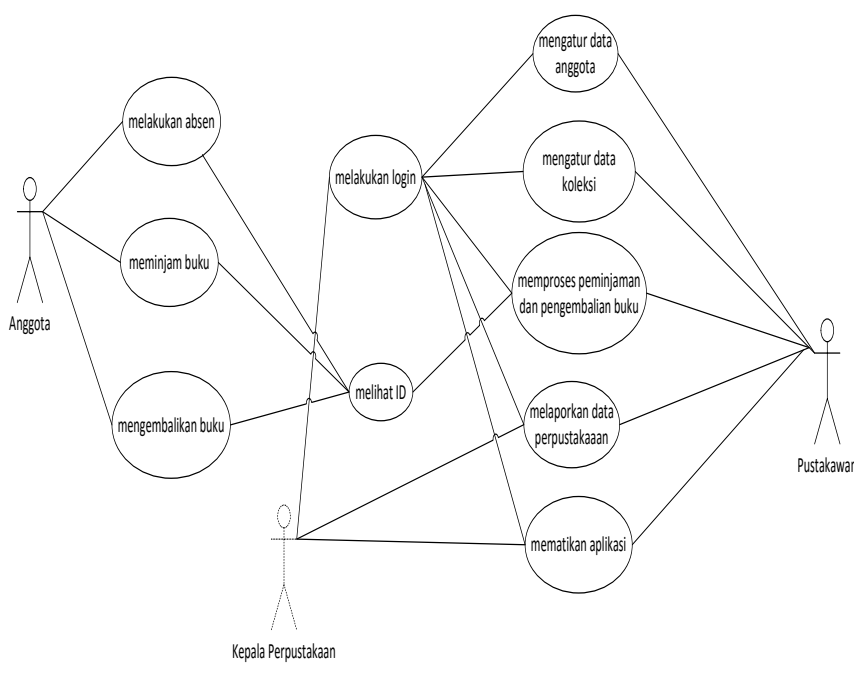

Gambar 4. Diagram Use Case

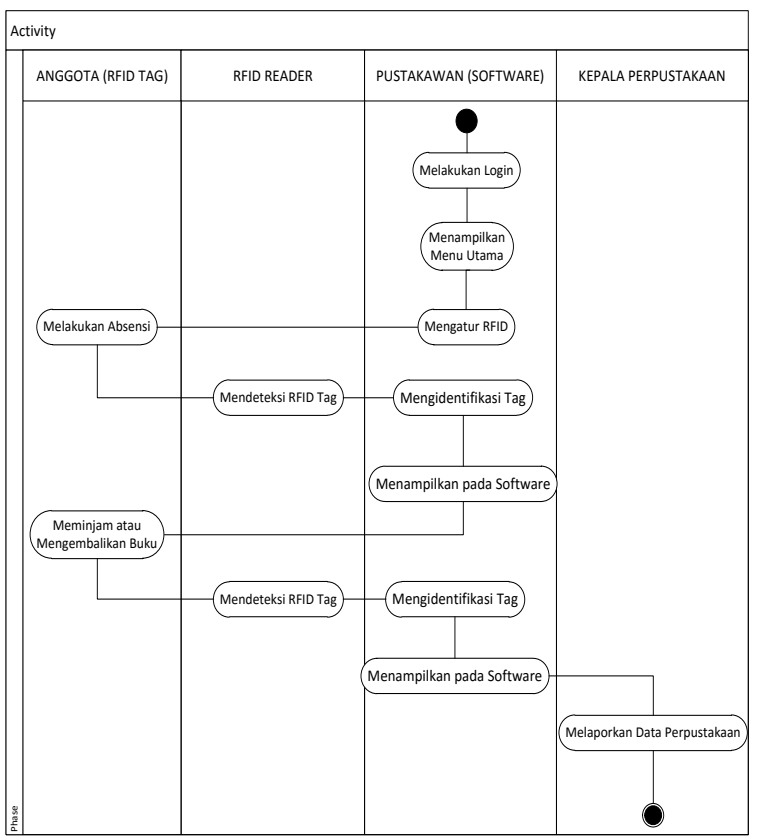

Gambar 5. Diagram Activity

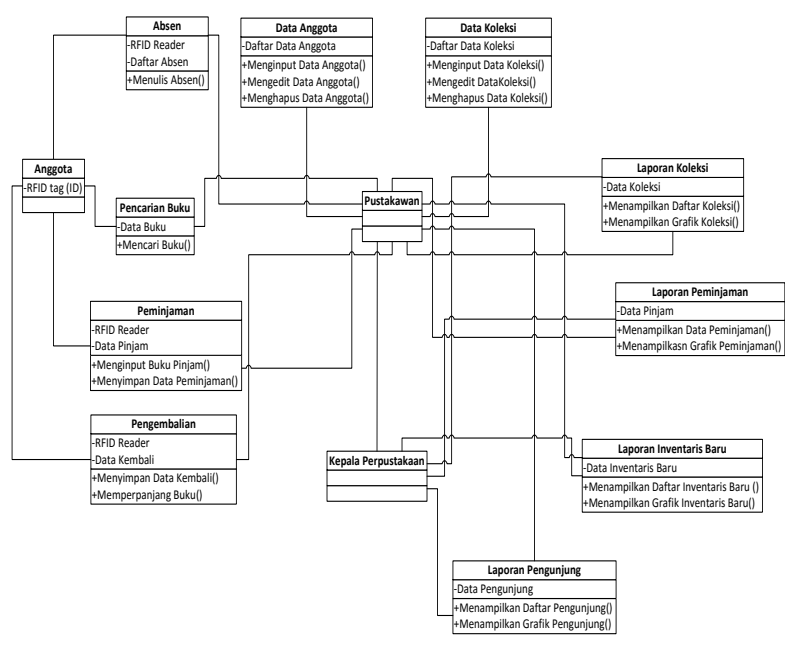

Gambar 6. Diagram Class

\section{Entity Relationship Diagram (ERD)}

\section{Entity Relationship Diagram} (ERD) adalah suatu pemodelan basis data yang digunakan untuk pengembangan sistem informasi. ERD juga sering digunakan pada untuk pemrosesan basis data bertipe relasional. ${ }^{[13]}$ Adapun ERD untuk sistem perpustakaan adalah sebagai berikut :

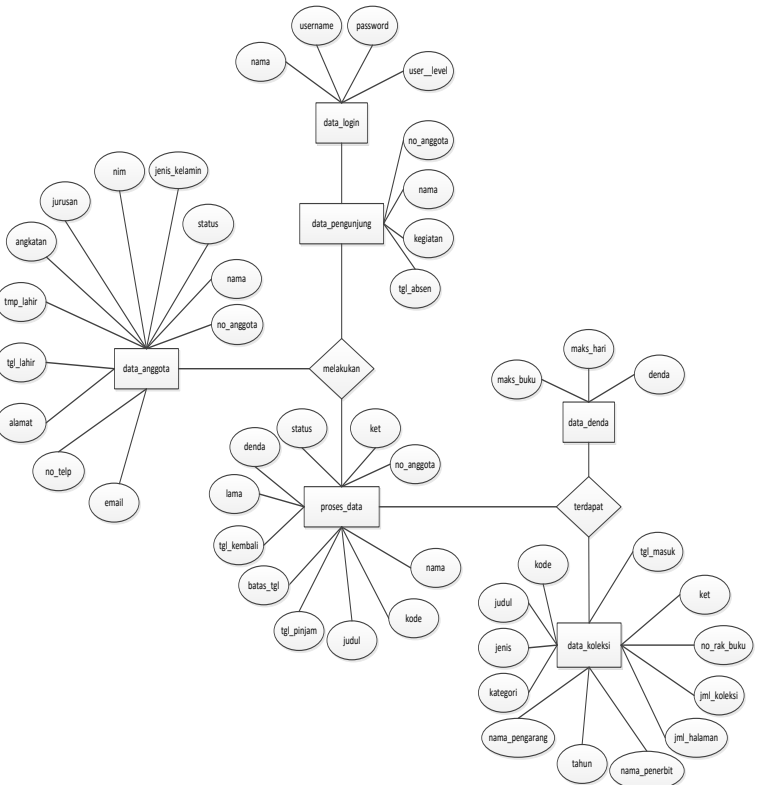

Gambar 7. Diagram ERD

\section{Perancangan Jaringan Komputer}

Jaringan komputer adalah sebuah kumpulan komputer, printer, dan peralatan lainnya yang saling terhubung dan dapat saling bertukar informasi maupun data dengan menggunakan protokol yang sama, pada tugas akhir ini menggunakan protokol TCP/IP. ${ }^{[6]}$ Jaringan komputer yang digunakan pada tugas akhir ini adalah client-server seperti yang gambar dibawah ini : 


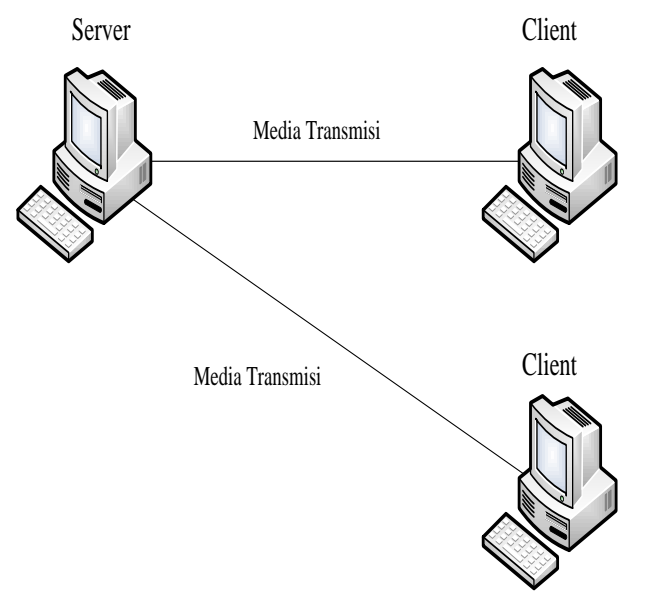

Gambar 8. Client Server

\subsection{Pembuatan Kode (Coding)}

Pembuatan kode dimaksudkan agar desain dapat diterjaemahkan ke bahasa pemrograman yang diketahui oleh komputer. Pembuatan tugas akhir mengggunakan bahasa pemrograman Java 2 Standar Edition yang digunakan untuk aplikasi desktop. Instrumen yang digunakan dalam pembuan yaitu menggunakan software NetBeans IDE 7.0.

\section{PENGUJIAN DAN PEMBAHASAN} APLIKASI

Pengujian adalah proses untuk mencari kesalahan terhadap suatu sistem dan memeriksa apakah suatu sistem tersebut sudah dibuat sesuai dengan keinginan. Pengujian yang dilakukan adalah sebagai berikut :

\subsection{Pengujian Terhadap User Requirement}

Tabel 1. User Requirement Perpustakaan

\begin{tabular}{|c|c|c|c|c|}
\hline \multirow{2}{*}{ No. } & \multirow{2}{*}{$\begin{array}{c}\text { User } \\
\text { Requirement }\end{array}$} & \multicolumn{2}{|c|}{$\begin{array}{c}\text { Hasil } \\
\text { Pengujian }\end{array}$} & \multirow{2}{*}{ Ket } \\
\hline & & Ada & $\begin{array}{l}\text { Tidak } \\
\text { Ada }\end{array}$ & \\
\hline 1. & Data Anggota & $\sqrt{ }$ & - & - \\
\hline 2. & Data Buku & $\sqrt{ }$ & - & $\begin{array}{l}\text { Data Buku } \\
\text { diinputkan } \\
\text { bersama } \\
\text { Data } \\
\text { Koleksi }\end{array}$ \\
\hline 3. & Data Koleksi & $\sqrt{ }$ & - & - \\
\hline 4. & $\begin{array}{l}\text { Absensi } \\
\text { Pengunjung }\end{array}$ & $\sqrt{ }$ & - & - \\
\hline 5. & $\begin{array}{l}\text { Data } \\
\text { Peminjaman }\end{array}$ & $\sqrt{ }$ & - & - \\
\hline 6. & $\begin{array}{l}\text { Data } \\
\text { Pengembalian }\end{array}$ & $\sqrt{ }$ & - & - \\
\hline 7. & $\begin{array}{l}\text { Laporan } \\
\text { Pengunjung }\end{array}$ & $\sqrt{ }$ & - & - \\
\hline 8. & $\begin{array}{l}\text { Laporan } \\
\text { Buku Baru }\end{array}$ & $\sqrt{ }$ & - & $\begin{array}{l}\text { Pada sistem } \\
\text { terletak } \\
\text { pada } \\
\text { laporan } \\
\text { koleksi } \\
\text { baru. }\end{array}$ \\
\hline 9. & $\begin{array}{l}\text { Laporan } \\
\text { Peminjaman }\end{array}$ & $\sqrt{ }$ & - & \\
\hline 10. & $\begin{array}{l}\text { Laporan } \\
\text { Koleksi }\end{array}$ & $\sqrt{ }$ & - & \\
\hline
\end{tabular}

Hasil pengujian antara sistem

yang dibuat dengan user requirement membuktikan bahwa kebutuhan pengguna sudah terpenuhi, dimana adanya data anggota, data buku, data koleksi, data peminjaman data pengembalian, dan laporan yang merupakan user requirement dari pustakawan. Adanya absensi pengunjung yang merupakan user requirement dari anggota, dan adanya laporan pengunjung, laporan buku baru, laporan peminjaman, dam laporan koleksi yang merupakan user requirement dari kepala perpustakaan. 


\subsection{Pengujian Terhadap Program}

Pengujian terhadap program menggunakan pengujian blcakbox karena pengujian ini memperlihatkan bahwa fungsi-fungsi dari perangkat lunak tersebut dapat beroperasi.

\section{Menu Login}

Hasil pengujian adalah bahwa menu login tidak mengalami error, karena setelah memasukkan username dan password dapat menuju ke bagian menu utama. Selain itu ketika pengguna mengalami kesalahan dalam memasukkan username atau password, maka akan kembali ke menu login.

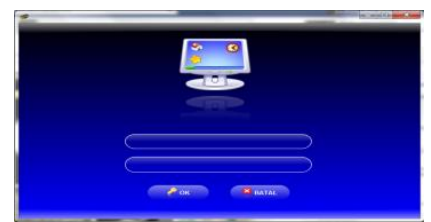

Gambar 9. Menu Login

2. Menu Jendela Utama

Hasil pengujian menu jendela utama adalah bahwa pustakawan dapat mengakses semua menu yang ada di jendela utama, sedangkan anggota dan kepala perpustakaan hanya dapat mengakses menu-menu tertentu saja. Pustakawan digunakan sebagai server sedangkan anggota dan kepala perpustakaan sebagai client.

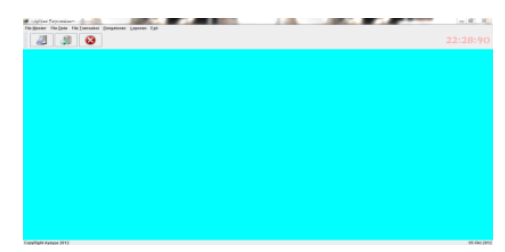

Gambar 10. Menu Jendela Utama

\section{Menu File Master}

a. Menu Data Anggota

Hasil pengujian menu data anggota adalah bahwa menu data anggota dapat digunakan untuk input, edit, dan hapus data berdasarkan tag.

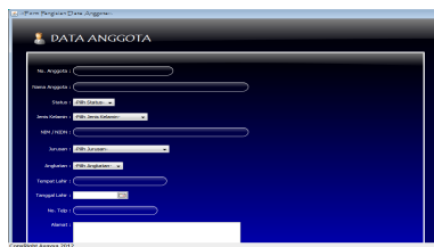

Gambar 10. Menu Data Anggota

b. Menu Data Koleksi

Hasil pengujian adalah bahwa menu data koleksi dapat melakukan input, edit, dan hapus data berdasarkan dengan kode.

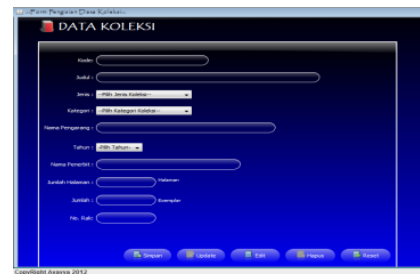

Gambar 11. Menu Data Koleksi

\section{Menu File Data}

a. Absensi Pengunjung

Hasil pengujian adalah bahwa anggota dapat menggunakan tag sebagai kartu anggota untuk melakukan absensi. 


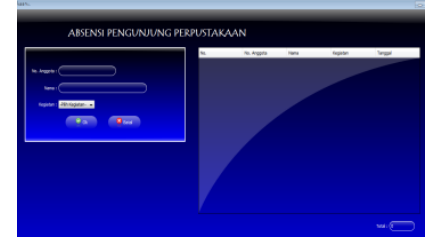

Gambar 12. Absensi Pengunjung

b. Pencarian Buku

Hasil pengujian adalah bahwa menu pencarian buku dapat digunaman untuk mencari buku dengan mengetikk judul, jenis, nama penerbit, dan nama pengarang.

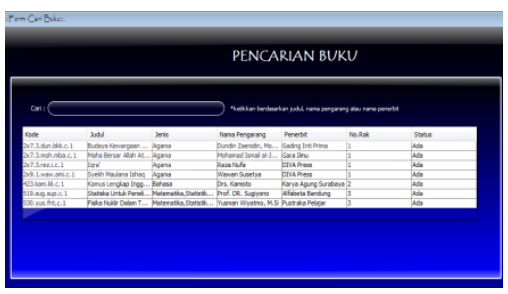

Gambar 13. Pencarian Buku

5. Menu File Transaksi

a. Data Peminjaman

Hasil Pengujian adalah bahwa tag dapat digunakan sebagai kartu anggota untuk transaksi peminjaman buku.

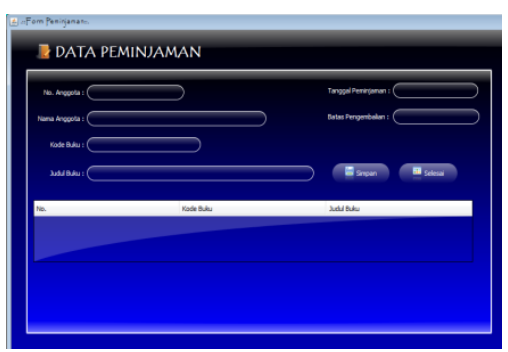

Gambar 14. Data Peminjaman

b. Data Pengembalian

Hasil Pengujian adalah bahwa tag dapat digunakan sebagai kartu anggota untuk transaksi pengembalian buku.

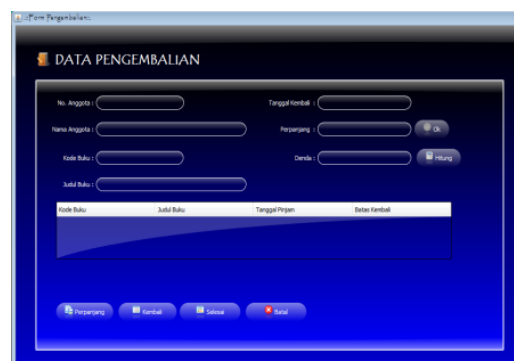

Gambar 15. Data Pengembalian

6. Menu Pengaturan

a. Pengaturan RFID

Hasil pengujian pengaturan RFID adalah keberhasilan pemilihan port yang digunakan RFID untuk menghubungkan antara RFID dengan software.

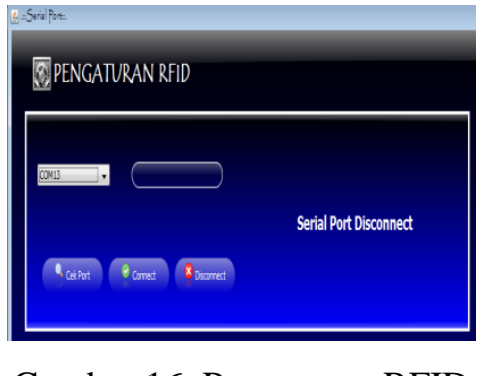

Gambar 16. Pengaturan RFID

b. Pengaturan Peminjaman

Hasil pengujian adalah keberhasilan input data,edit data, dan hapus data untuk maksimal buku, hari, dan denda. Maksimal buku, maksimal hari, dan denda digunakan untuk perhitungan pada proses data seperti peminjaman dan pengembalian.

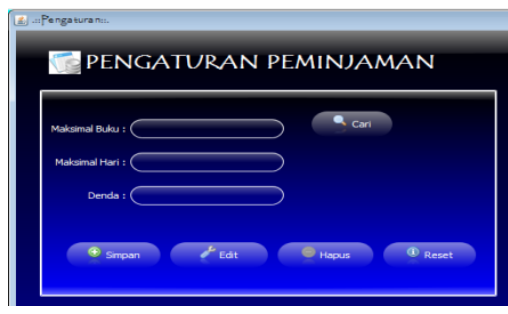

Gambar 17. Pengaturan Peminjaman 
c. Pengaturan User

Hasil pengujian pengaturan user adalah dapat digunakannya data pada pengaturan user untuk login aplikasi perpustakaan.

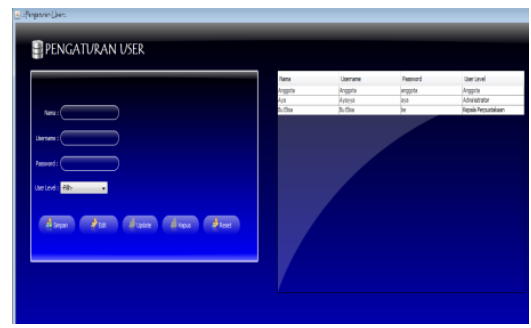

Gambar 18. Pengaturan User

7. Menu Laporan

a. Laporan Pengunjung

Hasil pengujian adalah bahwa laporan pengunjung dapat menampilkan data pengunjung sesuai dengan tanggal yang dipilih. Laporan ini ditampilkan dalam bentuk tabel dan grafik.

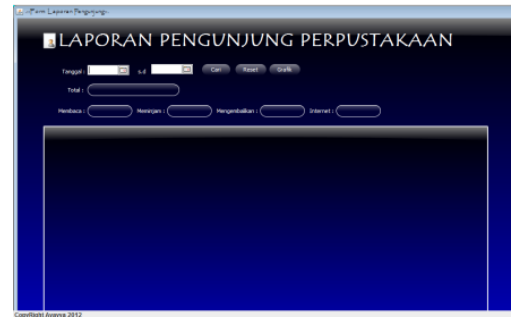

Gambar 19. Laporan Pengunjung

b. Laporan Koleksi Baru

Hasil pengujian adalah bahwa laporan koleksi baru dapat menampilkan data koleksi baru sesuai dengan tanggal yang dipilih. Laporan ini ditampilkan dalam bentuk tabel dan grafik.

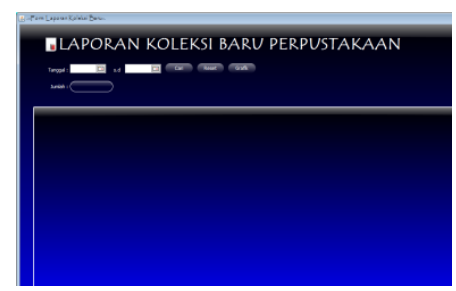

Gambar 20. Laporan Koleksi Baru

c. Laporan Peminjaman

Hasil pengujian adalah bahwa laporan peminjaman dapat menampilkan data peminjaman sesuai dengan tanggal yang dipilih. Laporan ini ditampilkan dalam bentuk tabel dan grafik.

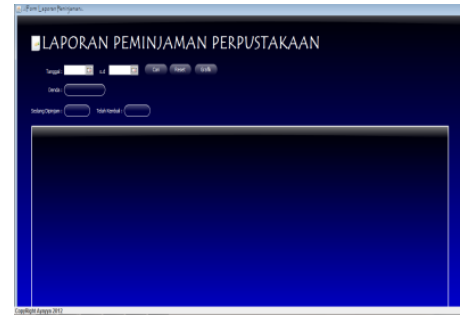

Gambar 21. Laporan Peminjaman

\section{d. Laporan Koleksi}

Hasil pengujian adalah bahwa laporan koleksi dapat menampilkan data koleksi perpustakaan sesuai dengan tanggal yang dipilih. Laporan ini ditampilkan dalam bentuk tabel dan grafik.

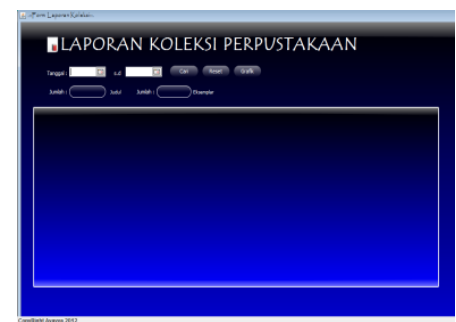

Gambar 22. Laporan Koleksi 
Menu exit terdiri dai 2 menu yaitu menu logout dan menu exit. Hasil pengujian adalah apabila pengguna menggunakan menu logout maka akan kembali ke menu login sedangkan jika menggunakan menu exit akan keluar ke dari aplikasi.

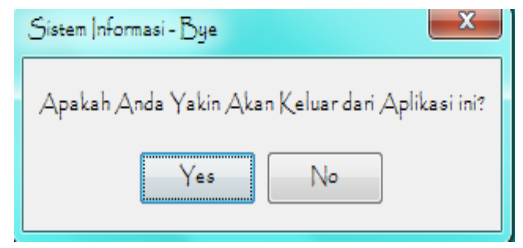

Gambar 23. Menu Exit

\subsection{Pengujian Terhadap Pengguna}

Pengujian ini dilakukan terhadap tiga pengguna atau user yang ada pada perpustakan. Pengguna tersebut meliputi pustakawan, anggota, dan kepala perpustakaan. Pengujian ini melihat apakah sistem yang dibuat dapat berjalan sesuai dengan fungsinya.

\section{PENUTUP}

Kesimpulan dari proses "Rancang Bangun Keanggotaan Perpustakaaan STT Telematika Menggunakan Rfid Berbasis Java 2 Standard Edition Dengan Konsep Client Server" yaitu :

1. Perancangan dan pengimplementasian Sistem Informasi Perpustakaan STT TELEMATIKA Purwokerto dengan menggunakan RFID dilakukan beberapa tahapan, diantaranya tahap perancangan aplikasi, perancangan database, perancangan jaringan, pembuatan struktur aplikasi, pembuatan aplikasi, dan pengujian aplikasi.
2. Pemanfaatan teknologi RFID untuk Sistem Informasi Perpustakaan STT TELEMATIKA Purwokerto adalah penggunaan RFID sebagai kartu anggota, dimana RFID yang digunakan adalah RFID reader dan RFID tag. RFID reader digunakan untuk membaca informasi yang dibawa RFID tag, sedangkan RFID tag digunakan untuk memancarkan informasi ke reader sehingga menimbulkan respon dari reader.

3. Penggunaan client server pada absensi pengunjung dan laporan. Server berada pada pustakawan dan client berada pada anggota dan kepala perpustakaan. Absensi pengunjung digunakan oleh anggota, sedangkan laporan (laporan pengunjung, laporan koleksi baru, laporan peminjaman, dan laporan koleksi baru) digunakan oleh kepala perpustakaan. Apabila anggota dapat melakukan absensi dan kepala perpustakaan dapat mengakses laporan, maka proses client server berhasil.

\section{DAFTAR PUSTAKA}

[1] A. Solichin, MySQL 5 Dari Pemula Hingga Mahir, Jakarta: Universitas Budi Luhur, 2010

[2] Anonymous, "Membuat Aplikasi Database denga Java," Penerbit ANDI, Yogyakarta, 2006.

[3] Anonymous, "Modul Rekayasa Perangkat Lunak". 
[4] Anonymous, "RFID Starter Kit," Inovative Electronic.

[5] Anonymous, "TCP/IP," TSI Perbankan.

[6] D. Ardiansyah, "Teknologi Jaringan Komputer," IlmuKomputer.Com, 2003.

[7] E. P. Nugroho, K. Ratnasari, K. N. Ramadhani and B. L. Putro, Rekayasa Perangkat Lunak, Bandung: Politeknik Telkom, 2009.

[8] E. Sutanta, Komunikasi Data \& Jaringan Komputer, Yogyakarta: Graha Ilmu, 2005.

[9] F. Rohman, "Perancangan Aplikasi Kamus Telekomunikasi Menggunakan Teknologi Java 2 Micro Edition (J2ME).," Akademi Teknik Telekomunikasi Sandhy Putra, Purwokerto, 2011.

[10] G. Utama, Berfikir Objek : Cara Menguasai Java, IlmuKomputer.com, 2002.

[11] I. Sofana, Teori \& Modul Praktikum Jaringan Komputer, Bandung: Penerbit Modula, 2011.

[12] J. K. Lamida, "Pengembangan Perangkat Lunak Pengelola Data Kehadiran Pegawai Jurusan Teknik Elektro Universitas Negeri Jakarta menggunakan Java dan RFID," Universitas NEgeri Jakarta, Jakarta, 2008

[13] J. Simarmata, Perancangan Basis Data, Yogyakarta: Penerbit ANDI, 2007.
[14] J. Sumarsono, Fisika untuk SMA/MA Kelas X, Jakarta : CV. Teguh Karya, 2009.

[15] K. Finkenzellerr, RFID Handbook, Third Edition, West Sussex: Wiley, 2010.

[16] M. Dr. Saifuddin Azwar, Metode Penelitian, Yogyakarta: Pustaka Pelajar, 2010.

[17] M. Rahmad Hakim S. \& Ir.Sutarto, Mastering Java, Jakarta : PT.Elex Media Komputindo, 2009.

[18] M. Sri Soejati, M. Dede Djuhana and M. Iwan Sugihartono, Catatan Kuliah Gelombang, Depok: Universitas Indonesia, 2004.

[19] R. S. Pressman, Rekayasa Perangkat Lunak Pendekatan Praktisi, Yogyakarta: Penerbit Andi, 2002.

[20] S. Dharwiyanti, "Pengantar Unified Modelling Language (UML)," IlmuKomputer.Com, 2003.

[21] S. Noviyanto, "Pengenalan Bahasa Pemrograman Java".

[22] S. Parno, Konsep Dasar Sistem Informasi.

[23] S. Rizky, Konsep Dasar Rekayasa Perangkat Lunak (Software Engineering), Jakarta: Prestasi Pustaka, 2011.

[24] Supriyono, "Penerapan Aplikasi RFID dibidang Perpustakaan," 2012. 